International Journal of Public Administration

\title{
Innovating Public Service Delivery in Transitional Countries: The Case of One Stop Shops in Kazakhstan
}

\section{Saltanat Janenova \& Pan Suk Kim}

To cite this article: Saltanat Janenova \& Pan Suk Kim (2016) Innovating Public Service Delivery in Transitional Countries: The Case of One Stop Shops in Kazakhstan, International Journal of Public Administration, 39:4, 323-333, DOI: 10.1080/01900692.2015.1064445

To link to this article: https://doi.org/10.1080/01900692.2015.1064445

Published online: 16 Feb 2016.

Submit your article to this journal $\sqsubset$

Џll Article views: 433

View Crossmark data $\complement$

Citing articles: 7 View citing articles ๘ 


\title{
Innovating Public Service Delivery in Transitional Countries: The Case of One Stop Shops in Kazakhstan
}

\author{
Saltanat Janenova ${ }^{\mathrm{a}}$ and Pan Suk Kim ${ }^{\mathrm{b}}$ \\ ${ }^{a}$ Graduate School of Public Policy, Nazarbayev University, Astana, Kazakhstan; ${ }^{b}$ College of Government and Business, Yonsei University, \\ Wonju, South Korea
}

\begin{abstract}
This article analyses the implementation of managerial ideas in Kazakhstan using the case of a combined public service delivery called "One Stop Shops". Several public services are provided in a single building rather than different government offices in a business-like style of service delivery and in a modern physical environment. The service integration policy is an attempt of Kazakhstani government to improve the quality of public services and reduce corruption. Some positive progress in improving the accessibility of public services has been noted. However, as this article argues, the country-specific model of "alternative-access" service delivery was not able to implement in-depth changes in the work of the public sector and improve service quality. Implementation of the managerial ideas has been limited and constrained by the institutional framework and culture prevailing in the Kazakhstani bureaucracy. The main conclusion is that the governments of transitional countries need to critically analyze the pros and cons of the new policies and reflect on their cultures before making further steps to adopt Western managerial initiatives.
\end{abstract}

\section{KEYWORDS}

Kazakhstan; one stop shop; public service delivery; transitional countries

\section{Introduction}

Following the paths of developed countries and under pressure imposed by the international donor agencies, a number of transitional countries have been trying to reshape their administrative systems along the logic of New Public Management (NPM). Kazakhstan has not been immune to the international trends of NPM and has adopted a managerial agenda as a key priority in the current administrative reform. Kazakhstan in Central Asia was the last of the Soviet republics to declare independence following the dissolution of the Soviet Union in 1991. Since then, it experienced a transitional process from a centrally planned economy to a market economy. Consequently, moving away from a command and control mode of government to integrated governance through multiple stakeholders is an emerging policy paradigm in Kazakhstan.

This article analyzes the implementation of the "One Stop Shop" (OSS) in the post-Soviet state of Kazakhstan. OSS is referred to in the legislation as a "Public Service Center" in Kazakhstan. In this article the term "One Stop Shop" is used along with the term "single-window." A one stop shop is an office where multiple services are offered and it was used in a number of developed countries several years ago. Since then, it has gradually spread to many developing countries. The public administration reform in Kazakhstan has introduced a new public sector organization, OSS, as an innovative approach to citizen-centered service delivery (Government, 2005). In the past, Kazakhstani citizens need to move almost all over government town to attain related services at different places so that a one stop shop became an attractive reform agenda in Kazakhstan. The term "OSS" is defined in this article as the provision of services and information of different government bodies through one location (Hagen \& Kubicek, 2000).

The OSS represents a counter service, in a modern and well-designed space, which is available for citizens, and which tries, in a more business-like atmosphere, to process citizens' requests for official documents, payment of registration fees, and similar services. The OSS has proved to be highly popular with citizens more used to being shunted from one public body to another by poorly motivated civil servants lacking in customer orientation (Knox, 2008). As of January 2014, the OSS provided access starting from 25 services of three stakeholders: Ministry of Justice (MJ) of the Republic of

CONTACT Pan Suk Kim pankim@gmail.com $\Theta$ Department of Global Public Administration, College of Government and Business, Yonsei University, Wonju Campus, Wonju 220-710,

South Korea.

(C) 2016 Taylor \& Francis 
Kazakhstan, a coordinator of reform (e.g. obtaining passports, birth/death/marriage certificates, registration of businesses); Agency for Land Resource Management (ALRM) (registration of land ownership and rent); and Ministry of Defence (MD) (registration of military servants in reserve) up to over 150 services of many other government bodies. Before recent government re-organisation in 2014, the coordinator of the OSS and egovernment policy implementation was the Agency for Informatization and Communication (AIC).

The purpose of this article is to examine the implementation of managerial ideas in a transitional context using the case of the service integration policy in Kazakhstan. The article is structured as follows. The progress of the policy implementation in Kazakhstan is examined from the perspective of the NPM. In this article two main research questions are addressed: (1) what characterizes service integration in a transitional context such as Kazakhstan; and (2) what has constrained public service integration in Kazakhstan? The first question is addressed by providing a brief overview of the public service modernization in transition countries followed by empirical data from the service integration process in Kazakhstan, which increases its complexity. The second question is answered in the discussion by analyzing the underlying reasons for the behavior and actions of policymakers in shaping the policy framework around their personal interests. The data was collected from interviews, participant observation, and documentary analysis.

\section{The challenges of managerial reforms for transitional countries}

While the adoption of NPM practices seems to have been beneficial in some cases, the NPM literature (Greer, 1994; Hood, 1991; Pollitt, 1993) shows that there is potential for, and real limitations to, applying such elements in transitional countries. The limited experience of NPM in such states suggests that there are institutional and cultural problems, whose persistence constrains implementation. It is argued that country-specific contexts influence the dynamics of NPM reforms, as policy implementation is firmly embedded in the societal, political, and economic circumstances of a particular point in time. The proponents of NPM see managerial reforms as providing a future for smaller, fast-moving service delivery organizations that would be kept lean by the pressures of competition and that would need to be user-responsive and outcome-oriented in order to survive. By contrast, the critics of NPM note concerns about the potential destabilizing effects of NPM, particularly for transition countries, such as increasing social inequality, corruption, and unmanageable change processes that could damage public service provision.

The central objective of change was the improvement in the ways in which the government is managed and services delivered, with emphasis on efficiency, economy, and effectiveness. Public services were provider-dominated, especially in the case of professionalized provision, where powerful, autonomous professions defended vested interests and could not be held to account (Pollitt, 1993). A new model emerged with different titles, such as "new public management" (Hood, 1991), "market-based public administration" (Lan \& Rosenbloom, 1992), "managerialism" (Pollitt, 1993), "reinventing government" (Osborne \& Gaebler, 1992), and the "post-bureaucratic" model (Barzelay, 1992). Whatever the title is, they provide similar premises, although there are significant country-specific variations and NPM's overall suitability for different regimes still remains uncertain.

Reformers face a number of challenges in repositioning public service recipients as customers. The limited experience of NPM in transitional states suggests that there are institutional constraints with implications for the capacity of central agencies to manage the process. Questions are raised whether the new model has sufficient conceptual coherence to provide an alternative to public administration as either a theoretical construct for academic research or an approach to the management of public services (McLaughlin, Osborne, \& Ferlie, 2002). Doubts are raised regarding its universal applicability for both public service and civil society failures (McCourt \& Minogue, 2002). Particularly, the applicability of the new model in the developing world has faced many problems, as many developing countries do not fulfill some preconditions for its effective implementation (Larbi, 1999). There are also socio-cultural constraints in reforming the administrative system along the NPM model. NPM initiatives are difficult to implement where there is social and cultural inertia (Ray, 1999; Zafarullah \& Huque, 2001). State-civil society relations also remain problematic. Civil society has not been able to put sufficient pressure on the state apparatus to implement reforms (Sozen \& Shaw, 2002).

Hence, the dynamic managerial model of social and economic development, which encourages building up a customer-orientated, transparent, quality-driven, and accountable government, has posed a fundamental challenge for a traditional model of administration in Kazakhstan, which is characterized as inefficient, costly, corrupt, and a patronage-based system (Cummings, 2005; Emrich-Bakenova, 2009; Perlman \& Gleason, 2007; Schatz, 2004). 


\section{Research sites and methodology}

Four single-window centers in Almaty, a former capital, and Astana, a new capital of Kazakhstan, were selected as in-depth case studies. Each OSS has a manager who is appointed by the AIC, three deputy managers, supervisor of customer service, and 40-60 frontline employees. In addition to the case studies to strengthen the external and internal validity of our data, 10 singlewindow centers at the regional level were examined to capture the general patterns of the change processes.

Case organizations are located in densely populated districts with easy access by public transport and limited parking space. The office buildings are visible from a distance because of their bright blue color amongst the surrounding gray apartment buildings. The opening times of the single-window center (from 9 am to $8 \mathrm{pm}$, Monday to Saturday, without a lunch break) are more convenient than the working hours of the government departments (normally from 9 am to $6 \mathrm{pm}$, Monday to Friday, with a two-hour lunch break). In fact, the civil servants at the government departments also continue to work until very late (around $8 \mathrm{pm}$ ) exceeding official working hours; however, they do not interact with customers during this time. Within this environment, the single-window organizations serve around 1,0001,200 clients on a daily basis. The public services provided through OSS vary from registration of legal documents, starting up a new business, application for social benefits (e.g. public housing, public nursery).

The research questions required detailed, empirical data, best collected through in-depth exploration of the issues with the selected participants. A number of primary sources were used to generate data for this article. Participant observation of the daily work practices within the case organizations provided first-hand insight into the challenges, tensions, and contradictions of the frontline customer service. In addition to the examination of the work practices in the case organizations, interviews with 10 managers of the single-window centers from different regions, 10 senior managers from the coordinating authority, and 25 frontline employees were conducted and analyzed. The rich data, combined with extensive secondary data in the form of policy documents, survey reports, and mass media publications, provided an opportunity to grasp a broad overview of the policy implementation from the views of those who have introduced legislative changes and those who implemented the policies in practice.

Anonymity and confidentiality were guaranteed to the research participants. Respondents were given a brief description of the research goals at the beginning of the interview and could refrain from answering questions. Semi-structured interviews, lasting for about an hour, were conducted in Russian, recorded, and often followed up with telephone calls. Data collection also included relevant legislation and organizational texts such as standards and regulations. All this data was integrated and analyzed in order to explore, in an inductive and contextual manner, the values and norms of the managerial culture and the processes of service integration versus interpretation by the managers and frontline employees.

Questions used in the semi-structured interviews included perceptions of the customer service, the challenges faced, and practices of managing service processes, as well as learning new ways of working. Questions were asked in the same way but in an open-ended manner without offering specific options for responses, so as to allow respondents to share their views in their own words. While the interview was structured around these standard questions, open discussions also developed around particular questions. Statements that were thought to indicate the respondents' views were extracted from the interview texts and categorized in a cross-case basis.

In the following stage of the analysis, the commonalities of each subject's narrative were interpreted further and compared with patterns identified during observations and in the organizational texts studied. Finally, in the contextualization stage, the patterns that were noted were applied back to the subjects' narratives to reveal how the meaning of customer service management and learning changes from participant to participant. The process of inductive categorization showed that similar patterns were evident in both case organizations, as well as OSS across regions.

\section{Key stages of policy implementation}

\section{Policy background}

There are a number of features about Kazakhstan that make it both an interesting and important location for the research (Dave, 2007). Kazakhstan is emerging as the most dynamic economic actor in Central Asia (Kazakhstan, Kyrgyzstan, Tajikistan, Turkmenistan, and Uzbekistan). It is the second largest country of the former Soviet Union, after the Russian Federation, and has rich natural resources, particularly oil and gas reserves, which are being exploited through massive foreign investment. Despite remarkable economic transformation under the leadership of President Nursultan Nazarbayev, in 2008 the overall poverty 
rate was estimated to be $15 \%$ of the population, exceeding $60 \%$ in some oil-rich rural regions (World Bank, 2008). Kazakhstan has the lowest social indicators in the regions of Europe and Central Asia (e.g. in terms of access to safe drinking water, incidence of tuberculosis and AIDS), illustrating the poor quality of socially significant public services, such as health and social care. One of the significant challenges for Kazakhstan in improving public service quality at lower cost is its small population size (16 million people) spread over a vast territory, which is equal in size to Western Europe ( 1 million square miles), with nearly half of the citizens, $43 \%$, living in the rural areas.

The political system of the country raises serious concerns among the academic community and is criticized for monopolizing political power and nepotism (Cummings, 2005; Emrich-Bakenova, 2009; Perlman \& Gleason, 2007; Schatz, 2004). General public dissatisfaction with the poor quality of public services delivered by the government bodies and public sector organizations (hospitals, schools, traffic police, tax bodies, etc.) has resulted in the formulation of a negative image of the government (Jandosova, Baitugelova, Jandosova, \& Kunitsa, 2002; Jandosova, Tagatova, \& Shilikbayeva, 2007). Accordingly, Kazakhstan is under growing pressure by the international community to engage in political reforms, which include a modernization agenda to improve the quality of public services (Knox, 2008). The President of Kazakhstan, Nursultan Nazarbayev, announced the new ambition for Kazakhstan to join the world's 50 most competitive countries (Nazarbayev, 2006a). Since January 2010, this has been particularly significant in light of the present chairmanship of Kazakhstan in the Organization for Security and Cooperation in Europe (OSCE), although serious concerns were raised that Kazakhstan could undermine the integrity of the OSCE's human rights principles (Kucera, 2009; Lillis, 2009). Hence, implementation of the public service integration policy is particularly challenging for Kazakhstan, compared to developed democracies given the transitional context of the country with its hierarchical, inertial, and corrupt public sector.

The OSS policy was initiated by President Nursultan Nazarbayev (Nazarbayev, 2005). Implementation of the OSS policy needs to be considered in relation to the changes that have taken place simultaneously in Kazakhstan within administrative reform. A range of new ideas, driven by the NPM ideology, such as development of performance standards, external audits of government bodies' performance, separation of strategic and operational functions, delegation of more autonomy to the managers, building partnerships between public and business sectors, etc., has been initiated by the young and ambitious members of the government. The assumption was that, "by paying more attention to clients, public service organisations will learn to deliver better results and that clients will notice the change and experience increased satisfaction" (Pollitt \& Bouckaert, 2000, 116).

The OSS policy was driven not only by aims to improve the cost-efficiency of administrative regulations and service quality, similar to other countries, but also by the political ambition to reduce the level of corruption. Given the widespread corruption in the public sector, criticized by international observers, Nazarbayev announced the aims of the OSS policy with a strong emphasis on combating corruption and, then, service quality improvement in the following way.

All regulations and bylaws, which intentionally or unintentionally create conditions for corrupt activities of officials, must be re-reviewed. Business must be separated from the civil service. It is necessary to fight with shadow businesses, their owners, shadow banking systems, multiplicity of permission documents, those who give bribes to avoid the law, etc. What can we do for this? It is necessary to create Public Service Centres based on the one stop shop arrangement, where in one place citizens can receive passports, national insurance numbers, driving licenses, etc. It can be done this year on a pilot basis in Astana and Almaty. (Nazarbayev, 2005).

The vision of the OSS as an anticorruption tool in the public sector was then reflected in the State AntiCorruption Strategy in Kazakhstan for 2006-2010. At the Plenary Session of the Foreign Investors Board, the President of Kazakhstan stated that the single-window centers were introduced to reduce personal contact between businesses and controlling authorities, and make the government more transparent (Nazarbayev, 2006b). The draft Concept for OSS Development, which had still not been approved by the end of the fieldwork, states that the main requirements for a priority list of services delivered at the OSS are: (1) the social and economic significance of the service (i.e. services aimed at protection of social, economic rights, and legal interests of citizens); (2) the mass demand of the service by customers; and (3) the corrupt nature of the service. All of these documents reflect the high expectations of the government on the OSS policy as a panacea for public service failures and corruption. Borrowing ideas from the NPM theory, the Kazakhstani OSS policy became a huge public campaign, through which the government intended to demonstrate to the international community, as well as to the public, its efforts to achieve a "more responsive and transparent bureaucracy". 


\section{Stages of policy implementation}

The OSS policy implementation process can be roughly divided into several stages: (1) the design of the policy vision and launch of the pilot projects (February 2005December 2006); (2) the OSS were assigned legal authorities to deliver 25 services and expanded from 30 to 300 offices and new channels of service access were introduced (January 2007-December 2008); (3) new stakeholders joined the OSS project with 32 services and new channels of service access were added (since January 2009); (4) the decentralizing of power over the OSS from the MJ to the local municipalities (since January 2010); (5) the recentralizing from the local municipalities to the MJ (in 2011); (6) the change of the coordinating authority to the Ministry of Transport and Communications (2011) and later to the Agency of Informatization and Communication; and (7) a combination of face-to-face and online customer service provision, 150 services through over 800 single-window centers.

Figure 1 illustrates that public service integration is a "policy-action continuum" with constant negotiation "between those seeking to put policy into effect, and those upon whom action depends" (Barrett \& Fudge, 1981, p. 25), in terms of types of services, methods of service delivery, and redistribution of power authorities among key actors. The government has made large investments into civil service training to bring new knowledge on service integration from different parts of the world (Germany, The Netherlands, United Kingdom, and Singapore) and adapt these ideas to the local political, societal, technological, and economic situation. Many of the variations of this basic idea have been successful in other countries in reducing administrative burdens on businesses and the public, especially on license and permit requirements. However, there was no universal concept of singlewindow arrangements that were implemented in a vast number of combinations and variations across developed and developing countries.

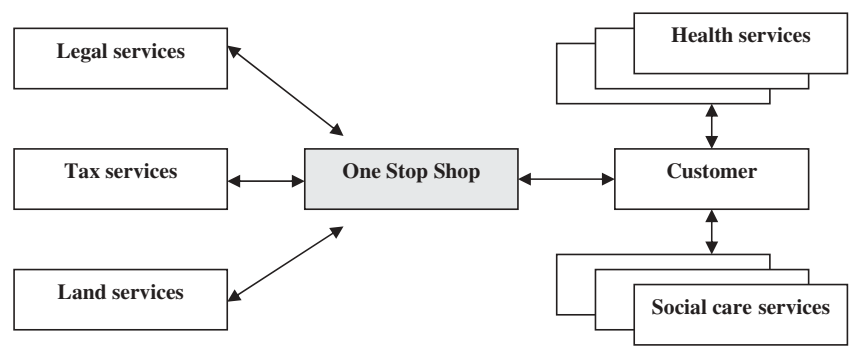

Figure 1. Single-access model of the OSS.
Traditional departments were accustomed to being separated by professional and organizational boundaries, in an environment of mistrust, lack of exchange of information, and in a constant battle with political leaders over power and resources. There was a lack of literature on the managerial reforms available in Russian and Kazakh languages. Information on public service reforms was available only through the participants of the study visits, a few international consultants, and Russian web sources. The pilot projects were launched in the four single-window centers: two offices in Astana and two in Almaty.

\section{Piloting a single-access model of service delivery}

Figure 1 presents a pilot model of the OSS as a singleaccess point of service delivery that functioned from November 2005 to December 2006. Figure 1 shows that the pilot OSS provided single, amalgamated access to the services of three stakeholder departments-MJ, ALRM, and the Tax Committee. These stakeholders worked in close cooperation with the single-window centers; however, they were still reluctant to share information about clients with each other. The frontline staff did not make decisions on applications and then the emphasis was on the quick and correct acceptance of applications, and the delivery of documents. From the very beginning of policy implementation, technical functions were assigned to the frontline employees, who played a role of "mediators" between service providers and customers (Janenova, 2008, 2009).

The strategic change from the earlier practice was delegation of frontline customer service to the OSS (consultation of customers, application submission) while other administrative processes on application review and decision-making remained in the traditional departments. A single access point at the OSS enabled clients to apply for a range of public services provided by the three stakeholders in one visit. It allowed customers to save time and costs, and avoid bureaucracy during their application for public services.

Large investments were put into the pilot projects, allocating the best resources in the public sector. The case organizations and other OSS, which were established at a later stage, were provided with modern offices, with new furniture and computer equipment. The stakeholders were obliged to send experienced staff to the new organization as team leaders for the duration of the pilot projects. Team leaders conducted intensive training for newly recruited staff and managers of the OSS on a range of services from the three different areas (legal, tax, and land registration). Foreign and local training institutions, as well as 
international consultants, delivered workshops on the international practice of service integration for the managers of the MJ and OSS.

Several important points regarding the impact of the service integration policy on the power dimensions between key actors need to be emphasized. First, in a certain way, the new single-window centers were competing with traditional departments in terms of better public service delivery. The OSS provided the same services, but their purpose was to provide better quality and transparent services in a more comfortable space and in more accessible ways. As was mentioned earlier, the opening times of the OSS ( 9 am to $8 \mathrm{pm}$, Monday to Saturday without a lunch break) were more convenient than those proposed by the traditional departments (normally 9 am to $6 \mathrm{pm}$, Monday to Friday with a two-hour lunch break). Politeness of the frontline employees presented a strikingly positive difference compared to the behavior of the traditional bureaucrats who were generally perceived as indifferent, rude, and unethical by the public (Jandosova et al., 2002).

Second, by being a single access point to public services, the OSSs were able to reduce personal contacts between civil servants and customers and corrupt opportunities for both sides. The frontline personnel were not able to influence the application review process, as they performed entirely technical functions by accepting and returning documents. The customers, as well as frontline workers, could not know who was going to review applications in the back offices, as documents were distributed among officials on a random basis. This does not mean that government officials could not still seek bribes to influence the results of an application review; however, now they performed corrupt actions with a much higher risk of being caught by the responsible authorities. Thus, the new policy encouraged traditional bureaucracy to become more transparent, more accountable, and more cost-efficient in delivering better-quality public services.

\section{Shift toward an alternative-access model}

Service delivery through a single access posed significant challenges for government officials, who were accustomed to working within strict professional and organizational boundaries. In the top-down, hierarchical and inertial public sector, civil servants were encouraged to shift professional organizational boundaries, initiate changes for service improvement, and learn to work in close cooperation with a range of stakeholders, including the business sector and NGOs. It is useful to remember that each partner in a collaborative undertaking has something at stake and brings in a host of preconceived notions to the partnership. The stakes may be reputation, but often entail more substantive considerations as resources (people and funds), turf, autonomy, or control (Bardach, 1998). Turf battles between politicians had a negative impact on the relationships between the front-office and backoffice staff. The political managers, as well as administrative civil servants, were concerned about losing their power, authority, and access to illegal payments. The ministers put strong pressure on the government to return their control authorities over service provision, justifying their arguments by the low level of professionalism among frontline employees. The front-office workers were considered by civil servants as "semiprofessionals" because they delivered a diversity of services without a university degree in these sectors, as opposed to the "professionals" who were educated and specialized within specific areas such as tax, land, or legal services. As a result of the strong resistance from politicians, the government replaced a single-access model with an alternative-access model (see Figure 2) that seemed to suit the interests of the political elite most of all (Government, 2007).

The key difference between the single-access model (Figure 1) and the alternative-access model (Figure 2) was the emergence of two new arrows linking the government bodies (departments of defense and land resource

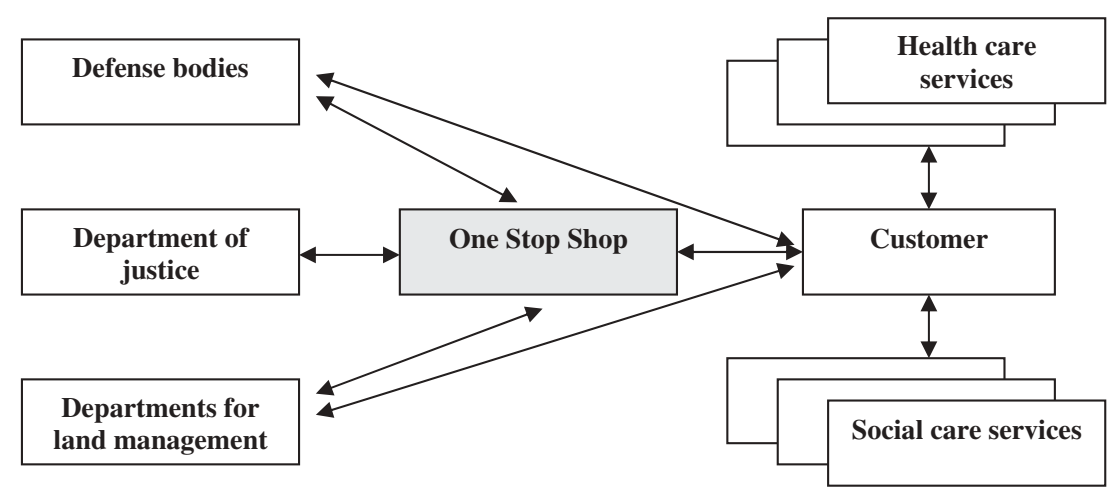

Figure 2. Alternative-access model of the OSS. 
management) and customers. From January 2007, public services were provided on an alternative basis, both at the responsible authorities and at OSS. Only the MJ being a policy coordinator continued to deliver services entirely through the single-window centers. The concept of the service integration policy was undermined by this strategic change in the policy design. This model enabled the stakeholders to deliver services directly to the customers and through OSS, which left opportunities for corrupt activities and constrained service improvement in terms of social inclusion and accountability. During the two years of policy implementation from 2005 to 2007, the OSS still continued to deliver only 25 services, including 16 services of the coordinating authority. The government still did not have a clear vision of the service integration development, and the process of negotiations was characterized by the antagonistic and contradictory relations among the stakeholders.

The President of Kazakhstan emphasized the need to increase the number of services delivered through OSS, which would enable a reduction in bureaucracy and make the work of the government more transparent. As a result, the government adopted the resolution that 32 new services of different state bodies would be provided through the single-window centers on an alternative basis from January 2009. The important observation is that the scope of new services included some social care services, such as the application for child benefits, registration for municipal housing, provision of health-care benefits for disabled people, and registration for public nursery care, thus indicating positive progress in making services more customer-oriented.

The strategic changes made in the design of the OSS policy, replacing the single-access model with the alternative-access model, had significantly undermined the idea of service integration and service improvement. The MJ, as a single driver of the service integration reform, was unable to overcome the resistance of the traditional bureaucracy. Many political managers disliked the enthusiasm of the MJ about service quality improvement, given their concerns about the rising power authority of the OSS. The single-access model of service provision, which was successfully piloted, was replaced by the less challenging and more acceptable alternative-access model that enabled the government bodies to continue to provide services directly to the customers and through OSS on an alternative basis, and engage in illegal practices.

\section{Present model: Toward e-government}

Currently, all OSS services are provided online through an e-government system. Some services are still delivered on an alternative basis: through both OSS and government bodies, most services are delivered now on a single-access basis. An e-government program has been in place since 2006 to provide citizens with fast and reliable access to public services online. This has included the creation of a network of public electronic centers where people without direct access to the Internet can avail themselves of online services, examples of which are: filing tax returns and making tax payments, pension fund deductions, property registration, and setting up a business (Knox, 2008).

Since the launch of the new policy in 2004, Kazakhstan has made good progress in modernizing and improving public services. According to the United Nations E-Government Survey 2014 (UN, 2014), Kazakhstan has improved its position in the e-government development rating from $81^{\text {st }}$ position in 2008 to $28^{\text {th }}$ position out of 192 in 2014; in terms of the e-participation index, Kazakhstan was in the $22^{\text {nd }}$ position in 2014 (United Nations, 2014). Ranked $6^{\text {th }}$ in Asia in general and first in Central Asia, Kazakhstan is the only country in Central Asia showing improvements between 2012 and 2014; and jumping from a global ranking of $38^{\text {th }}$ in 2012 to $28^{\text {th }}$ in 2014 (United Nations, 2014).

Heeks (2003) notes that it is important to examine the technological infrastructure of the country given the significant role of information and communication technologies in improving the activities of public sector organizations and their agents. The expected outcome of e-government policy is building an integrated government, which enables information to be gathered and shared across departments, and public services to be reorganized and joined together in an integrative manner. Thus, the technological infrastructure in the country can enable or constrain service integration as a means to overcome distance and assist vulnerable groups in remote locations to get access to the public services.

The main challenges faced by Kazakhstan at the initial stage were low computer literacy, limited access to Internet, and poor technological infrastructure. In 2004-2006 at the launch of e-government policy, the digital divide in Kazakhstan was dramatic: the level of computer literacy of the population was $4.3 \%$; the level of Internet usage was 2.8\%; there was poor technological infrastructure, and the Internet and mobile communication was extremely costly (Decree, 2004). Despite high scores on the Human Capital Index in the UN E-government Survey 2014 (99.73\% of adult literacy and $93.95 \%$ of gross enrollment), the level exceeding some developed countries, Kazakhstan's Online Service Index was not high; it was ranked $67^{\text {th }}$ out of 192 countries (United Nations, 2014). 
Thus, the significant challenge for Kazakhstan has been the continuing and widening digital divide defined by Fink and Kenny (2003) as a gap in access to ICT, the ability to use ICT, its actual use, and the impact of its use. Following the Programme on Reducing the Digital Gap in the Republic of Kazakhstan for 2007-2009, the government has taken a number of measures to improve computer literacy and popularize Internet usage among the population (Government, 2007). These measures included cost reduction for Internet use and computers, expansion of channels of Internet access via dial-up phone technology, mobile phones, public access points introduced at the OSS, free training for different target groups of the population, computerization of $100 \%$ of public schools, and encouragement of good practices in developing e-services among government bodies. All services provided through OSS are avallable through the e-government portal.

There is a growing recognition among the government bodies of the importance of providing relevant and up-to-date information. Information on spending national and local budgets is now publicly available on the website of the Ministry of Finance (www.minfin. $\mathrm{kz}$ ). Laws, policies, and other documentation of interest to the citizens on education, health, social welfare, and other sectors are increasingly being integrated within the overall national portal and on the agency portals. For example, applications for the Presidential Scholarship Program "Bolashak" ("Future" from Kazakh), which aims to support young talented Kazakhstani citizens in Master and PhD study abroad, are now accepted online via the e-government portal as well as in the Center for International Programs.

\section{Pros and cons of the country-specific model}

What are the political and social implications of the service integration policy? The new policy in Kazakhstan was driven by the NPM appeal of "better services for less cost", combined with the political ambitions to reduce corruption in the civil service. The political leadership considered single-window arrangements as a panacea for public service failures and poor performance of the state apparatus. The new policy was also exploited as a demonstration of the government's dedication to promoting transparency and public accountability for the citizens and, more importantly, the international community.

Certain positive achievements in terms of public service provision have been made within a short period of policy implementation: (1) information about public services has become more transparent; (2) the physical customer service environment has significantly improved; (3) public services have become more accessible both through face-to-face interaction and e-government system; (4) staff have learned new knowledge and skills to deliver a diversity of services in one place and work across different professions and organizations; and (5) the consultation mechanism has become more transparent (involvement of international experts, political parties, and business associations).

However, the research evidence shows that the OSS policy has not been implemented to its full extent. Several important points need to be raised in this regard. The introduction of the single-access service delivery model, where public services were accessible only through OSS, was a successful achievement of the policy at the pilot stage. The single-access model had real potential to reduce the risk of corruption by eliminating direct contact between service providers and customers, improve the quality of services by enabling equal access and social inclusion, and improving the accountability of the public sector by creating reliable monitoring systems of government performance data. However, the single-access model was replaced by the country-specific alternative-access model, which seemed to suit the interests of the political elite much better compared to the pilot model. The OSS seemed to offer a sort of choice for citizens to choose services at the new public sector organization or traditional departments. They provided the same services as the traditional authorities, but in a more comfortable space and in more accessible ways. However, service quality has been improved in terms of accessibility and speed of delivery by putting services together in one physical location rather than making changes in the administrative processes in the back-offices. The traditional bureaucrats continued to work without challenging their work practices from the customers' perspective. Where many countries have introduced more resultoriented management and set up evaluation criteria for performance, the government of Kazakhstan really concentrated its attention on improvement of the frontline service delivery, without considering changes in the back offices.

In the NPM theory evaluation of customer satisfaction is one of the techniques to yield important data and improve quality. While the government declared the customer-orientation principle as a slogan for public service reform, the citizens continued to be ignored in the policymaking process. The OSS services were selected without an evaluation of customers' needs. The single-window centers introduced standards and regulations as performance measures following NPM ideology. However, performance evaluation could not 
provide transparent and reliable information, as it contained partial information because of the alternative model, which enabled the government bodies to avoid OSS when delivering services. The officials continued to have control over statistical data on their performance, with limited access both by the public and by the central government. Furthermore, the traditional bureaucrats could continue illegal practices as they had direct interactions with clients and were able to influence the results of the application review.

The research findings show that the service integration policy has not been able to change service production processes, mainly because change, to a greater extent, was not desirable for the traditional bureaucracy. The service integration policy has posed fundamental challenges to traditional bureaucracy: (1) it competes with the government bodies in the provision of the same services, but produces better quality, in terms of accessibility, speed of delivery, and public accountability; (2) it has the potential to reduce corruption; and (3) it can provide reliable and transparent information on the performance data of the stakeholders. Hence, in the top-down, hierarchical, and corrupt system, the service integration policy that promoted transparency, public accountability, and social equality has been constrained by the institutional framework and culture of the traditional bureaucracy.

\section{Conclusion}

The purpose of this article was to analyses the implementation of the managerial ideas in Kazakhstan, using the case of the service integration policy. The research evidence shows that the extent to which NPM ideas were imported was limited and constrained by the institutional framework and culture prevailing in the Kazakhstani bureaucracy. Despite remarkable economic transformation under the leadership of President Nursultan Nazarbayev and many positive developments in the country-such as rising standards of living and improved quality of public services, Kazakhstan is now facing a number of challenges that are threatening the sustainability of the country, including growing regional disparities in wealth distribution, a high poverty rate-particularly in rural areas, corruption, and limited participation of civil society in policy processes. The OSS policy has been an attempt of the Kazakhstani government to reduce red tape in the civil service and improve the quality of public services.

The aim of the article was to critically examine the progress and evolution of the OSS policy implementation in the transitional context of Kazakhstan, identify challenges faced by the government in modernizing public services, and summarize lessons learnt from the Kazakhstani practice. OSS policy implementation in the Kazakhstani context is dynamic; there have been several changes in policy and procedures, such as the introduction of single-access and alternative-access models of service delivery, integrating with e-services. The OSS policy has changed the traditional pattern of public service delivery when services were provided only by the professionals with special education and through face-to-face interaction. The new policy has had significant impact on the entire Kazakhstani public sector by stimulating cooperation across professional and organizational boundaries. New technologies, standards, and procedures have introduced new ways of service delivery through single-window arrangements and new ways of interacting among service providers, as well as between service providers and customers.

OSS policy in Kazakhstan was driven both by the global trends for managerial reforms and by countryspecific political, organizational, technological, and cultural factors. The global drivers for integrated service provision in Kazakhstan were diverse. These included globalization, pressure from the international community, public dissatisfaction with the government, and the opportunities offered by the technologies for shifts in service delivery. A combination of these factors influenced the government's intention to turn to the opportunities presented for integrated working. The concepts of clear targets, performance indicators, and transparency collided with a culture that was strongly influenced by legal control, a patronage system, and bureaucratic administrative procedures.

The OSS policy implementation still lacks customerorientation and consultation with users. There is a lack of surveys initiated by the government on the views of customers about their choice of public services, channels of delivery, and quality of received service. Political leadership pushing the government bodies to integrate services rapidly sometimes lacks consideration of limiting factors like scarce resources, path dependencies, legacy systems, and public agencies' time constraints. This may have negative impact on the quality of integrated services as the development of trust between service providers requires time.

This article presents a snapshot not only of the OSS policy implementation but of the overall political and administrative situation in Kazakhstan. This research revealed striking similarities in Kazakhstan with other transitional countries in terms of facing both institutional and socio-cultural constraints during the implementation of managerial reforms. While lacking knowledge and state capacity, the Kazakhstani government anxiously embraced OSS policy as a panacea for 
public service failures, ineffectiveness, and corruption. Kazakhstan has made good progress forward in terms of public service modernization; however, it still has a long way to go to the integrated government, which is clean of corruption and oriented to the customers.

Since the situation in the Kazakhstani political system is rather similar to the situation in other postSoviet countries, except for the Baltic States, the findings of this research might be of particular interest for academics and practitioners who are interested in managerial reforms and policy implementation issues in post-communist countries. The pilot model of the single-access service provision had more potential to reduce corruption and improve the quality of public services, compared to the existing alternative access model, which best suited interests of the political elite.

Serious questions were raised concerning the ability to initiate changes by the service integration approach in the inertial and centralized context. Because of the transition and political ambitions to engage in democratic reforms, there has been significant pressure from the political leadership to introduce a service integration governance agenda, without leaving sufficient time to analyze and adopt this idea in depth. The ineffective personnel management practices and the prevailing common values in the Kazakhstani civil service made the situation even more complex. The Kazakhstani government risks investing huge amounts in public service modernization and setting up new technologies without any real cost-benefit outcomes in service quality for citizens, whose needs were ignored following the traditional administrative pattern. The overall conclusion for transitional countries is that critical thinking and an in-depth analysis of the public sector and specific cultures are required before Western managerial reforms can be implemented. Otherwise the government risks falling into the trap of "fashionable approaches", while overestimating the positive outcomes of the new ideas and underestimating the negative drawbacks.

\section{References}

Bardach, E. (1998). Getting agencies to work together. Washington, DC: Brookings Institution Press.

Barrett, S. M., \& Fudge, C. (1981). Policy and action: Essays on the implementation of public policy. London, UK: Methuen.

Barzelay, M. (1992). Breaking through bureaucracy: A new vision for managing in government. Berkeley, CA: University of California Press.

Cummings, S. (2005). Kazakhstan: Power and the elite. London, UK: I.B. Tauris.
Dave, B. (2007). Kazakhstan: Ethnicity, language and power. London, UK: Routledge.

Decree of the President of the Republic of Kazakhstan. (2004). On state programme of building-up e-government in the Republic of Kazakhstan for 2005-2007, No.1471, 10 November, Astana, Kazakhstan.

Emrich-Bakenova, S. (2009). Trajectory of civil service development in Kazakhstan: Nexus of politics and administration. Governance, 22, 717-745. doi:10.1111/gove.2009.22. issue- 4

Fink, C., \& Kenny, Ch. J. (2003). W(h)ither the digital divide. Info, 5(6), 15-24. http://dx.doi.org/10.1108/1463669031 0507180

Government of the Republic of Kazakhstan. (2005). Establishment of public service centres on a pilot basis by the ministry of justice, tax committee and agency for land resource management. Government Resolution, Astana, Kazakhstan.

Government of the Republic of Kazakhstan. (2007). Establishment of state entities - Public service centres of the ministry of justice. Government Resolution No. 1, Astana, Kazakhstan.

Greer, P. (1994). Transforming central government. Buckingham, UK: Open University Press.

Hagen, M., \& Kubicek, H. (2000). One stop government in Europe: Results from 11 national surveys. Bremen, Germany: University of Bremen.

Heeks, R. (2003). eGovernment for development: Causes of eGovernment success and failure: Factor model. IDPM, University of Manchester, UK. Retrieved from http:// www.egov4dev.org/causefactor.htm.

Hood, C. (1991). A public management for all seasons? Public Administration, 69, 3-19. doi:10.1111/padm.1991.69.issue-1

Jandosova, J., Baitugelova, N., Jandosova, F., \& Kunitsa, S. (2002). Perceptions of corruption in Kazakhstan: By parliamentarians, public officials, private business and civil society. Almaty, Kazakhstan: Sange Research Centre and United Nations Development Programme. Retrieved April 15, 2009, from http://www.sange.kz/newspic/Report_ Corruption_rus.pdf

Jandosova, J., Tagatova, A., \& Shilikbayeva, N. (2007). Administrative barriers as sources for corrupt practices in civil service. Almaty, Kazakhstan. Retrieved April 15, 2009, from http://www.sange.kz/newspic/Administrative_bar riers_2006.pdf

Janenova, S. (2009). One stop shop in Kazakhstan: Breakingup traditional bureaucracy or a new look for old practice? Paper presented at the Social Policy Association conference "Policy Futures: Learning from the Past?", University of Edinburgh, UK, 29 June-1 July 2009. Retrieved July 10, 2009, from http://www.socialpolicy.ed.ac.uk/ conferences\#2009

Janenova, S. (2008). The Kazakh one stop-shops: Challenges and recommendations. In B. G. Peters (Eds.), Mixes, matches and mistakes: New public management in Russia and the former soviet republics (pp. 117-150). Budapest, Hungary: Open Society Institute. Retrieved April 15, 2009, from http://lgi.osi.hu/publications/2008/395/Peters_com plete_WEB.pdf

Knox, C. (2008). Kazakhstan: Modernizing government in the context of political inertia. International Review of 
Administrative Sciences, 74, 477-496. doi:10.1177/0020 852308095314

Kucera, J. (2009, May 14). Kazakhstan: Evaluating Astana's democratisation intentions (Eurasia Insight). Retrieved May 20, 2009, from http://www.eurasianet.org/depart ments/insightb/articles/eav051409a.shtml

Lan, Z., \& Rosenbloom, D. (1992). Editorial: Public administration in transition? Public Administration Review, 52, 535-537. doi:10.2307/977163

Larbi, G. (1999, September). The new public management approach and crisis states (United Research Institute for Social Development Discussion Paper, No.112). Retrieved April 15, 2009, from http://www.pogar.org/publications/ other/unrisd/dp112.pdf

Lillis, J. (2009, December 3). Kazakhstan: Has Astana met its OSCE pledges? (Eurasia Insight). Retrieved December 5, 2009, from http://www.eurasianet.org/departments/ insight/articles/eav120309.shtml

McCourt, W., \& Minogue, M. (2002). The internationalization of public management: Reinventing the third world state. Cheltenham, UK: Edward Elgar.

McLaughlin, K., Osbourne, S., \& Ferlie, E. (2002). New public management: Current trends and future prospects. London, UK: Routledge.

Ministry of Transport and Communications. (2011). Resolution on the committee for control of public services automatisation and coordination of the one stop shops under the ministry for communication and information. Astana, Kazakhstan: Ministry of Transport and Communications.

Nazarbayev, N. (2005). Kazakhstan on the road to accelerated economic, social and political modernisation. Address of the President of Kazakhstan, Nursultan Nazarbayev, to the people of Kazakhstan, February 18, 2005, Astana, Kazakhstan. Retrieved from http://www.akorda.kz/en/ addresses/addresses_of_president/page_address-of-the-pre sident-of-the-republic-of-kazakhstan-nursultan-nazar bayev-to-the-people-of-kazakhstan-february-18-2005_ 1343986671

Nazarbayev, N. (2006a). Kazakhstan's strategy of joining the world's 50 most competitive countries: Kazakhstan is on the threshold of a major breakthrough in its development.
Address of the President of Kazakhstan, Nursultan Nazarbayev, to the people of Kazakhstan, March 1, 2006, Astana, Kazakhstan. Retrieved from http://www. akorda.kz/en/addresses/addresses_of_president/page_ address-of-the-president-of-the-republic-of-kazakhstannursultan-nazarbayev-to-the-people-of-kazakhstanmarch-1-2006_1343986805

Nazarbayev, N. (2006b). Presidential speech at the 21st plenary session of the foreign investors board, Astana, Kazakhstan.

Osborne, D., \& Gaebler, T. (1992). Reinventing government: How the entrepreneurial spirit is transforming the public sector. Reading, MA: Addison-Wesley.

Perlman, B., \& Gleason, G. (2007). Cultural determinism versus administrative logic: Asian values and administrative reform in Kazakhstan and Uzbekistan. International Journal of Public Administration, 30, 1327-1342. doi:10.1080/01900690701229475

Pollitt, C. (1993). Managerialism and the public services: Cuts or cultural change in the 1990s? Oxford, UK: Blackwell.

Pollitt, C., \& Bouckaert, G. (2000). Public management reform: A comparative analysis. Oxford, UK: Oxford University Press.

Ray, B. (1999). Good governance, administrative reform and socio-economic realities: A South Pacific perspective. International Journal of Social Economics, 26, 354-369. doi:10.1108/03068299910229749

Schatz, E. (2004). Modern clan politics: The power of "Blood" in Kazakhstan and beyond. Seattle, WA: University of Washington Press.

Sozen, S., \& Shaw, I. (2002). The international applicability of 'New' public management: Lessons from Turkey. International Journal of Public Sector Management, 15, 475-486. doi:10.1108/09513550210439625

United Nations. (2014). UN E-government survey 2014. New York, NY: United Nations.

World Bank. (2008). Kazakhstan at a glance (Country Report). Retrieved April 15, 2009, from http://devdata. worldbank.org/AAG/kaz_aag.pdf

Zafarullah, H., \& Huque, A. S. (2001). Public management for good governance: Reforms, regimes, reality in Bangladesh. International Journal of Public Administration, 24, 13791403. doi:10.1081/PAD-100105944 